\title{
Collaborative model for a two-echelon supply chain with uncertain demand under carbon tax policy
}

\author{
ARINDAM GHOSH ${ }^{1,2, *(D)}, \mathrm{S}$ P SARMAH ${ }^{2}$ and $\mathrm{J} \mathrm{K} \mathrm{JHA}^{2}$ \\ ${ }^{1}$ Department of Operations and IT, ICFAI Business School (IBS) Hyderabad, ICFAI Foundation for Higher \\ Education (IFHE), Shankerpally Road, Hyderabad, India \\ ${ }^{2}$ Department of Industrial and Systems Engineering, Indian Institute of Technology Kharagpur, Kharagpur, \\ India \\ e-mail: arindamiitan@gmail.com; spsarmah@iem.iitkgp.ernet.in; jkjha@iem.iitkgp.ernet.in
}

MS received 5 December 2017; revised 26 February 2018; accepted 2 April 2018; published online 20 July 2018

\begin{abstract}
Consideration of carbon policies while optimizing supply chain operations has become imperative as governments and regulatory bodies throughout the world have implemented different carbon policies to reduce emissions of greenhouse gasses, especially $\mathrm{CO}_{2}$. "Carbon tax" is one of the major carbon policies, initiated by several governments to curtail emissions. In this study, we have considered this policy to optimize the total expected cost (TEC) of a two-echelon integrated supply chain with stochastic demand, where both backorders and lost sales are permitted. An unconstrained mixed integer non-linear programming (MINLP) problem is formulated and further solved to find the optimal production rate, order quantity, number of shipments and reorder point while minimizing the TEC. Emissions from all the major sources such as production, inventory and transportation have been taken into consideration. It is assumed that the emission from production is a function of production rate, and emission from transportation depends on payload and vehicle type. This study will help organizations to reduce cost and emissions, and regulatory bodies to decide proper tax rate on carbon emission.
\end{abstract}

Keywords. Supply chain; carbon emission; carbon tax; random demand; variable production rate.

\section{Introduction}

Global warming is a major concern in recent times among the common people in general and research community in particular. Scientists have revealed that over the past 130 years, the average temperature of the earth has raised by $0.85^{\circ} \mathrm{C}$. It is anticipated that between the years 2030 and 2050 nearly 250000 deaths will take place annually due to a drastic change in weather. Melting of glaciers, rising of sea levels and extreme weather conditions are the result of global warming [1]. Emission of anthropogenic greenhouse gasses, especially $\mathrm{CO}_{2}$, is the main cause of global warming and air pollution [2]. Human activities are responsible for global warming and pollution, which have driven governments and different regulatory bodies to take initiatives and set realistic targets to curb carbon emission. The Kyoto protocol, a part of the United Nations Framework Convention on Climate Change (UNFCCC), is targeted to reduce emissions by $8 \%$ from 1990 levels by the year 2012 . Scientists have suggested an even more aggressive target of reduction of $25 \%$ emission from 1990 levels by 2020 [3].

*For correspondence
Various governments have imposed different carbon policies to materialize this target.

The most common carbon policies are carbon tax, carbon cap and carbon cap-and-trade [2, 4]. The biggest international scheme for the trading of greenhouse gasses is European Union Trading Systems (EU-ETS), which was initiated in 2005, follows the "cap-and-trade" concept, where companies get an upper limit on emissions and beyond this limit, companies are penalized. If companies emit less than the specified limit, they can sell it off or keep as unused allowance [5]. On the other hand, United States has imposed a revenue-neutral carbon tax, where every tonne of carbon dioxide is chargeable [6]. Compared with other policies, the carbon tax mechanism is simple and easy to implement. The carbon tax mechanism bids stable carbon prices; hence, organizations can make investment planning without any concern of fluctuating regulatory costs [7]. In the case of strict carbon cap policy, the regulatory bodies set a carbon emission cap on an organization and penalty for exceeding the cap is infinitely large [8]. Hence, organizations are bound to emit within the given level under strict carbon cap policy. Apart from stringent laws, organizations are striving to bring sustainable practices into their operations due to customer 
awareness, profitability and stiff competitions [9-11]. Initially, all the "green" initiatives were organization-centric. However, in recent days, organizations cannot compete solely as individual establishments as today's businesses are supply chain (SC) oriented. Most of the business houses are part of one or more SCs, and 50\% of the industrial added values are derived from SCs [12]. Hence, incorporation of environmental aspects into SC has become essential for sustainable business. Organizations like Walmart, Tesco and Unilever run supply-chain-oriented businesses, and they take serious initiatives to implement sustainable practices across their SCs [13-15]. Hence, the concept of managing SCs under different carbon policies is gaining momentum. Among different carbon policies, carbon taxes and carbon markets (carbon cap-and-trade) are recognized as the most cost-effective mechanisms [16]. In this work, we have considered carbon tax policy. Recent research works have revealed that a carefully designed carbon policy has great positive impact on emission in an SC [17]. Countries across the world have implemented this policy to reduce emissions of carbon, and offered subsidies for products that consume lesser energy [18].

In this paper, we have considered a two-echelon integrated SC with stochastic demand to minimize the total expected cost (TEC) by simultaneously optimizing production rate, order quantity, reorder point and number of shipments under carbon tax policy. In the recent years, several authors have discussed on how operational adjustments can take care of economical as well as environmental issues. In the following section, we discuss the burgeoning literature on integrating different carbon policies into production-inventory models.

The rest of the paper is organized as follows. The related literature is elaborated in section 2. Section 3 presents assumptions and notation. Section 4 deals with model formulation and solution technique. Section 5 demonstrates numerical examples and sensitivity analyses. Section 6 concludes and also discusses about some managerial insights and future directions.

\section{Literature review}

In the domain of production-inventory literature, papers dealing with carbon policies are still sparse but growing rapidly. Here, we have discussed briefly some recent works in the area of production-inventory models with different carbon policies. Dobos [19] introduced tradable permits of carbon in the well-known Arrow-Karlin production-inventory model. Dobos [20] further extended the earlier work in two ways: first, the author considered time-dependent unit tradable permit and secondly the author calculated instantaneous cost of procured environmental licenses. In both the papers the author considered multi-period single-stage production-inventory models. Diabat and Simchi-Levi [21] developed a optimal model for an SC to minimize opportunity cost considering carbon cap. Hua et al [22] discussed managing carbon emissions in inventory handling under the carbon trade policy. Wahab et al [23] incorporated screening and holding cost of defective items in their model taking the fixed and variable carbon costs in their model. Abdallah et al [24] developed a model for a green SC to determine production and shipment lot sizes for raw materials and finished products assuming carbon emission constraints. Bouchery et al [25] reformulated the classical EOQ formula taking sustainability issues into account while incorporating both carbon cap and carbon price mechanisms. Benjaafar et al [26] considered carbon tax, strict cap on emission, cap-and-trade and carbon-offset policies to determine optimal production, inventory, backorder quantity and amount of carbon traded to minimize the total SC cost for a single firm and also extended their models for multiple firms with or without coordination. Chen et al [8] depicted how with operational adjustments emissions can be reduced without significant increase in cost under different carbon policies. Jaber et al [5] developed a model to determine the optimal manufacturer's production rate and vendor-buyer coordination multiplier under carbon tax, emission allowance trading, emission penalty and combination of carbon tax and emission penalty. Toptal et al [27] extended the basic EOQ model with carbon emission reduction investment under carbon cap, carbon tax and cap-and-trade policies. Du et al [2] developed a model using game theoretical approach for centralized and decentralized decisions of the manufacturer and the retailer in an SC where both the parties induce low-carbon efforts. Hammami et al [28] formulated a deterministic multi-period model considering both carbon cap and carbon tax policies with lead time constraint in an SC.

Most of the papers in the area of production-inventory management with carbon policies have considered deterministic demand. In reality, organizations often experience stochastic demand due to shrinking product life cycles, buying patterns of customers, seasonality and other issues [29]. Therefore, we have considered that the demand on the buyer is stochastic. Recently, the following few papers have considered random or stochastic demand to capture more realistic aspects while considering different carbon policies. Rosič and Jammernegg [30] optimized a dual sourcing problem with carbon tax and carbon cap-and-trade policies under stochastic demand in the newsboy environment. Zhang and $\mathrm{Xu}$ [31] also considered stochastic demand while developing a multi-item production planning model to maximize profit with carbon trading cost, and assumed newsvendor-type products while formulating the model. Arikan and Jammernegg [32] developed a single-period inventory model considering product carbon footprint constraint taking demand as a positive random variable. Dong et al [33] developed a profit maximization multi-stage SC model assuming 
Table 1. A comparison of the study with study with some related works in the area of production-inventory management.

\begin{tabular}{|c|c|c|c|c|c|}
\hline \multirow[b]{2}{*}{ Author(s) } & \multicolumn{3}{|c|}{ Sources of carbon emission } & \multicolumn{2}{|c|}{ Demand } \\
\hline & Production & Inventory & Transportation & Deterministic & Uncertain \\
\hline Dobos [19] & $\mathrm{Y}$ & & & $\mathrm{Y}$ & \\
\hline Dobos [20] & $\mathrm{Y}$ & & & $\mathrm{Y}$ & \\
\hline Hua et al [22] & $\mathrm{Y}$ & $\mathrm{Y}$ & & Y & \\
\hline Wahab et al [23] & & & $\mathrm{Y}$ & $\mathrm{Y}$ & \\
\hline Abdallah et al [24] & & & $\mathrm{Y}$ & $\mathrm{Y}$ & \\
\hline Bouchery et al [25] & & $\mathrm{Y}$ & & $\mathrm{Y}$ & \\
\hline Benjaafar et al [26] & & $\mathrm{Y}$ & & $\mathrm{Y}$ & \\
\hline Chen et al [8] & $\mathrm{Y}$ & $\mathrm{Y}$ & & $\mathrm{Y}$ & \\
\hline Jaber et al [5] & $\mathrm{Y}$ & & & $\mathrm{Y}$ & \\
\hline Rosič and Jammernegg [30] & & & $\mathrm{Y}$ & & $\mathrm{Y}$ \\
\hline Zhang and Xu [31] & $\mathrm{Y}$ & & & & $\mathrm{Y}$ \\
\hline Arikan and Jammernegg [32] & $\mathrm{Y}$ & $\mathrm{Y}$ & $\mathrm{Y}$ & & $\mathrm{Y}$ \\
\hline Dong et al [33] & & & & & $\mathrm{Y}$ \\
\hline Toptal et al [27] & & $\mathrm{Y}$ & & Y & \\
\hline Du et al [2] & & & & Y & \\
\hline Hammami et al [28] & $\mathrm{Y}$ & $\mathrm{Y}$ & $\mathrm{Y}$ & $\mathrm{Y}$ & \\
\hline Purohit et al [34] & & $\mathrm{Y}$ & & & $\mathrm{Y}$ \\
\hline This study & $\mathrm{Y}$ & $\mathrm{Y}$ & $\mathrm{Y}$ & & $\mathrm{Y}$ \\
\hline
\end{tabular}

carbon-cap-and-trade policy and stochastic demand in single-period planning horizon. Purohit et al [34] developed a mixed integer programming model to optimize an inventory lot-sizing problem in a multi-period setting with non-stationary stochastic demand condition under cycle service level constraints considering carbon cap-and-trade policy. The literature review reveals that the authors have considered stochastic demand with different carbon policies either in single-period or multi-period time horizon. To our knowledge, only a few authors in the literature considered carbon policies with random/stochastic demand in infinite planning horizon.

In this paper, we considered infinite planning horizon and stochastic demand. The demand follows normal distribution and shortage is partially backordered. It is frequently conceived that the demand for the fast moving item constitutes a large number of smaller demands from individual customers, so from the central limit theorem, the resulting demand follows normal distribution [35]. When shortage takes place at the buyer side, some of the loyal customers may wait till the orders get fulfilled in the next replenishment cycle while the other customers may go somewhere else to satisfy their demand. In reality, it will be more generic to assume a combination of these two situations, where some of the demands are backordered and the rest are lost during the stock out period [36].

Emissions from production, inventory and transportation are the major sources of carbon emission in an SC and they are either Scope 1 or Scope 2 emissions. Scope 1 emissions are the emissions that arise directly from the sources that are owned by the organization and Scope 2 emissions come from consumption of purchased electricity (electricity consumption for warehousing the inventory). In reality, organizations can measure and mitigate all Scope 1 and Scope 2 emissions; but among the aforementioned papers very few have dealt with emissions from all the three major sources. In table 1, the sources of emissions and type of demand considered by the different authors in their study have been summarized. Table 1 also reveals that in the extant literature, very few papers have considered uncertain demand while modelling production-inventory problems. Among these papers, presented in table 1, very few papers $[28,32]$ have dealt with all major sources of emission (production, inventory and transportation). The emission from production can be adjusted by controlling the production rate and the emission from transportation depends on vehicle type, payload and vehicle velocity, which have been overlooked in the literature while modelling production-inventory models in SC.

In our work we have considered random demand and also taken into account emissions from all the major sources under carbon tax policy. We have simultaneously determined optimal production rate, number of shipments, order quantity and reorder point while minimizing the $T E C$ for the entire SC and thereby our work is different from the earlier and contributes to the existing knowledge of literature. In spite of our sincere efforts we have not found any paper in the area of the production-inventory problem that has considered all these afore-mentioned decision variables simultaneously. In table 2 we have further chosen some works, discussed earlier, which have considered uncertain demand to juxtapose with our study.

As mentioned earlier we have considered emissions from production, inventory and transportation. Here emission 
Table 2. A comparison of the present study with some related works with stochastic/random demand.

\begin{tabular}{|c|c|c|c|c|c|c|c|}
\hline \multirow[b]{2}{*}{ Author(s) } & \multicolumn{5}{|c|}{ Decision variables } & \multicolumn{2}{|c|}{$\begin{array}{c}\text { Number of } \\
\text { echelon }\end{array}$} \\
\hline & $\begin{array}{l}\text { Production } \\
\text { rate }\end{array}$ & $\begin{array}{l}\text { Number of } \\
\text { shipments }\end{array}$ & $\begin{array}{l}\text { Order } \\
\text { quantity }\end{array}$ & $\begin{array}{c}\text { Reorder } \\
\text { point }\end{array}$ & Others & Single & Multiple \\
\hline $\begin{array}{l}\text { Rosič and } \\
\text { Jammernegg [30] }\end{array}$ & & & $\mathrm{Y}$ & & & $\mathrm{Y}$ & \\
\hline Zhang and Xu [31] & & & & & $\begin{array}{l}\text { Production quantity, amount of } \\
\text { carbon traded }\end{array}$ & $\mathrm{Y}$ & \\
\hline $\begin{array}{l}\text { Arikan and } \\
\text { Jammernegg [32] }\end{array}$ & & & $\mathrm{Y}$ & & & & $\mathrm{Y}$ \\
\hline Dong et al [33] & & & $\mathrm{Y}$ & & Sustainability level & $\mathrm{Y}$ & \\
\hline This study & $\mathrm{Y}$ & $\mathrm{Y}$ & $\mathrm{Y}$ & $\mathrm{Y}$ & & & $\mathrm{Y}$ \\
\hline
\end{tabular}

from production (tonne/unit) is considered as a function of production rate; a similar proposition has been considered by different authors in the literature [5, 37]. Also, it is assumed that emission from transportation depends on vehicle velocity; in the existing literature, many papers such as Jabali et al [38] and Ligterink et al [39] have considered the same proposition. We have also presumed that emission from inventory is linearly related to the total inventory in the SC. In the literature, many authors [8, 20] have considered the same assumption. In spite of our sincere efforts, we have not found any paper that has considered carbon tax policy under random demand for an SC in infinite planning horizon, where the emission from production is a function of production rate, and the emission from transportation depends on vehicle's velocity, payload and vehicle type, and thereby this work tries to bridge this gap in the literature.

\section{Notation and assumptions}

The following notations are used to develop the model.

\section{Notation}

$D \quad$ average demand rate on the buyer

$S \quad$ the vendor's set-up cost per production set-up

$A$ the buyer's ordering cost per order

$L \quad$ lead time of the buyer

$b$ fraction of the demand during the stock out period that will be backordered, $0 \leq b \leq 1$

$\eta(r)$ expected demand shortage at the end of each cycle of the buyer

$\theta \quad$ the buyer's shortage cost per unit short

$\theta_{0} \quad$ the buyer's profit per unit

$\sigma \quad$ standard deviation of demand per unit time

$x \quad$ the lead time demand, which follows a normal distribution with finite mean $D L$ and standard deviation $\sigma_{L}$, where $\sigma_{L}$ denotes the standard deviation of demand during lead time, $\sigma_{L}=\sigma \sqrt{L}$ $t_{0} \quad$ transportation cost per unit time when the vehicle is empty

$t_{Q} \quad$ transportation cost per unit item per unit time when the vehicle is loaded

$d$ distance between the vendor and the buyer

$v \quad$ velocity of the vehicle (truck)

$p \quad$ production cost per unit item

$h_{b} \quad$ the buyer's holding cost per unit item per unit time

$h_{v} \quad$ the vendor's holding cost per unit item per unit time

$\alpha_{b} \quad$ carbon emission per unit item per unit time due to inventory at the buyer

$\alpha_{v} \quad$ carbon emission per unit item per unit time due to inventory at the vendor

$\lambda$ minimum production-demand ratio, where $\lambda \geq 1$

$T_{x} \quad$ tax paid due to a single unit of emission (\$/tonne)

\section{Decision variables}

$m$ number of shipments per production cycle (a positive integer)

$r$ reorder point of the buyer

$Q$ the buyer's ordering quantity per order

$P \quad$ the vendor's production rate

Some notations have been introduced later as and when required.

Assumptions

(i) There is a single vendor and single buyer, and they deal with a fast moving item.

(ii) The buyer orders a lot of size $Q$ and the vendor produces $m Q$ units with a finite production rate $P(P>D)$ in one production set-up but ships in quantity $Q$ to the buyer over $m$ times as shown in figure 1 . The buyer reviews inventory continuously and an order is placed when the on hand inventory drops to the reorder point $r$.

(iii) Any demand not met from stock is partially backordered during the stock out period.

(iv) Production, inventory holding and transportation are the sources main of emission. 
(v) Emission from production is a function of production rate, and emission from transportation depends on payload and type of the vehicle.

\section{Model formulation and solution procedure}

In this section, a mathematical model is formulated to find out the optimal order quantity and reorder point of the buyer, production rate of the vendor and the number of shipments between the vendor and the buyer to minimize the TEC of the $\mathrm{SC}$ while considering tax for carbon emission.

Figure 1 depicts the production, shipment and inventory variation patterns at the vendor and the buyer. The buyer orders a lot of size $Q$, the vendor produces the item in a lot of size $m Q$ at a constant production rate $P$ in each production cycle and ships to the buyer in $m$ lots each of size $Q$. The first lot of size $Q$ is ready for shipment after $Q / P$ units of time after the start of the production, and then the vendor continues the delivery on average every $Q / D$ units of time. The TEC per unit time for the SC comprises the expected costs per unit time for the buyer and the vendor.

The TEC per unit time of the buyer is the sum of ordering cost, inventory holding cost, shortage cost and lost profit, which can be expressed as follows:

$$
\begin{aligned}
T E C_{b}(Q, r)= & \frac{A D}{Q}+h_{b}\left[\frac{Q}{2}+(r-D L)+(1-b) \eta(r)\right] \\
& +\frac{\theta D}{Q} \eta(r)+\frac{\theta_{0}(1-b) D}{Q} \eta(r) .
\end{aligned}
$$

When the lead time demand follows normal distribution, the expected backorders or lost sales per cycle can be obtained as

$$
\begin{aligned}
\eta(r) & =\int_{r}^{\infty}(x-r) f(x) d x \\
& =\sigma_{L} f\left(\frac{r-D L}{\sigma_{L}}\right)+(D L-r) G\left(\frac{r-D L}{\sigma_{L}}\right),
\end{aligned}
$$

where $f(x)$ and $G(x)$ are the standard normal density function and the complementary cumulative distribution function of the standard normal distribution, respectively.

Similarly, the TEC per unit time of the vendor comprises set-up cost, production cost, inventory holding cost and transportation cost. Among these cost components, the expressions for the cost of set-up and production are selfexplanatory. Derivations of inventory holding cost and the transportation costs are shown as follows.

The vendor's average inventory per unit time is evaluated from figure 1 as the difference of the vendor's accumulated inventory and the buyer's accumulated inventory [40] and can be written as $\frac{Q}{2}\left[m\left(1-\frac{D}{P}\right)-1+\frac{2 D}{P}\right]$.
Thus, the inventory cost at the end of vendor per unit time can be expressed as

$$
I_{v}=h_{v} \frac{Q}{2}\left[m\left(1-\frac{D}{P}\right)-1+\frac{2 D}{P}\right] .
$$

For developing the model, it is assumed that transportation cost will be borne by the vendor. For a round trip, the cost incurred by the vendor for transportation can be expressed as

$$
T_{v}=t_{0}\left(\frac{d D}{v Q}\right)+t_{Q}\left(\frac{d D}{v}\right) .
$$

Therefore, the total cost incurred by the vendor per unit time can be given as

$$
\begin{aligned}
T C_{v}(Q, m, P)= & \frac{S D}{m Q}+p D+h_{v} \frac{Q}{2}\left[m\left(1-\frac{D}{P}\right)-1+\frac{2 D}{P}\right] \\
& +t_{0}\left(\frac{d D}{v Q}\right)+t_{Q}\left(\frac{d D}{v}\right) .
\end{aligned}
$$

The total expected traditional two-echelon SC cost (without emission-related cost) can be determined by adding total cost incurred by the buyer and total cost incurred by the vendor and expressed as

$$
\begin{aligned}
& T E C_{\text {Traditional }}(Q, r, m, P) \\
& +h_{b}\left[\frac{Q}{2}+r-D L+(1-b) \eta(r)\right] \\
& +\frac{\theta D}{Q} \eta(r)+\frac{\theta_{0}(1-b) D}{Q} \eta(r) \\
& +\frac{S D}{m Q}+p D+h_{v} \frac{Q}{2}\left[m\left(1-\frac{D}{P}\right)-1+\frac{2 D}{P}\right] \\
& +t_{0}\left(\frac{d D}{v Q}\right)+t_{Q}\left(\frac{d D}{v}\right)
\end{aligned}
$$

Next, we derive expression for the emissions from different sources, and then derive the total expected emission from the entire SC. As discussed earlier, the emission (tonne/unit) due to production can be expressed as a function of production rate $(P)$ [37] as $\pi=p_{1} P^{2}-p_{2} P+p_{3}$, where $p_{1}, p_{2}, p_{3}$ are emissions parameters in tonne.year ${ }^{2} /$ unit $^{3}$, tonne-year/unit ${ }^{2}$ and tonne/unit, respectively, related to production.

The total expected emission from inventory is linearly proportional to the average inventory holding per unit time by the buyer and the vendor and can be expressed as

$$
\begin{aligned}
T E E_{I}= & \alpha_{b}\left[\frac{Q}{2}+r-D L+(1-b) \eta(r)\right] \\
& +\alpha_{v} \frac{Q}{2}\left[m\left(1-\frac{D}{P}\right)-1+\frac{2 D}{P}\right] .
\end{aligned}
$$


The emissions (tonne/kilometre) from transportation can be expressed as a function of velocity $v$ and can be given as $K(v)=\left(a_{0}+a_{1} v+a_{2} v^{3}+\frac{a_{3}}{v^{2}}\right)$. The coefficients
The $T E C$ for the entire SC comprises the traditional cost as given in Eq. (4) and the tax given for emitting carbon as in Eq. (6) and can be written as follows:

$$
\begin{aligned}
& T E C(Q, r, m, P)=\frac{D}{Q}\left[A+\frac{S}{m}+\theta \eta(r)+\theta_{0}(1-b) \eta(r)+t_{0} \frac{d}{v}\right] \\
& +p D+h_{b}\left[\frac{Q}{2}+r-D L+(1-b) \eta(r)\right]+t_{Q}\left(\frac{d D}{v}\right) \\
& +h_{v} \frac{Q}{2}\left[m\left(1-\frac{D}{P}\right)-1+\frac{2 D}{P}\right]+T_{x}\left[\begin{array}{l}
\left(p_{1} P^{2}-p_{2} P+p_{3}\right) D+\alpha_{b}\left[\frac{Q}{2}+r-D L+(1-b) \eta(r)\right] \\
+\alpha_{v} \frac{Q}{2}\left[m\left(1-\frac{D}{P}\right)-1+\frac{2 D}{P}\right]+\frac{2 d D}{Q}\left(a_{0}+a_{1} v+a_{2} v^{3}+\frac{a_{3}}{v^{2}}\right)
\end{array}\right] .
\end{aligned}
$$

$\left(a_{0}, a_{1}, a_{2}, a_{3}\right)$ vary depending on vehicle's type and size. Here, we have considered a heavy duty truck with 32-42 tonnes payload and the value of the $\mathrm{CO}_{2}$ emissions coefficients for this particular vehicle category can be given as $\left(a_{0}, a_{1}, a_{2}, a_{3}\right)=(1576,-17.6,0.00117,36067) 10^{-6}$ [38].

Now, the total expected carbon emission (in tonne) per unit time from these sources can be expressed as follows:

$$
\begin{aligned}
\operatorname{TEE}(Q, m, r, P)= & \left(p_{1} P^{2}-p_{2} P+p_{3}\right) D \\
& +\alpha_{b}\left[\frac{Q}{2}+r-D L+(1-b) \eta(r)\right] \\
& +\alpha_{v} \frac{Q}{2}\left[m\left(1-\frac{D}{P}\right)-1+\frac{2 D}{P}\right] \\
& +\frac{2 d D}{Q}\left(a_{0}+a_{1} v+a_{2} v^{3}+\frac{a_{3}}{v^{2}}\right) .
\end{aligned}
$$

The objective is to minimize $\operatorname{TEC}(Q, r, m, P)$ as obtained in Eq. (7).

\subsection{Solution procedure}

Equation (7) is a convex function in $Q$ and $r$ as shown in "Appendix A". Differentiating Eq. (7) with respect to $Q$ and $r$, respectively, and then equating to 0 one gets

$$
Q=\left[\frac{2 D\left(A+\frac{S}{m}+\theta \eta(r)+\theta_{0}(1-b) \eta(r)+\frac{t_{0} d}{v}+2 T_{x} d\left(a_{0}+a_{1} v+a_{2} v^{3}+\frac{a_{3}}{v^{2}}\right)\right)}{h_{b}+T_{x} \alpha_{b}+\left(h_{v}+T_{x} \alpha_{v}\right)\left(m\left(1-\frac{D}{P}\right)-1+\frac{2 D}{P}\right)}\right]^{\frac{1}{2}}
$$

Since the tax per unit (tonne) emission is $T_{x}$, the total expected tax paid for the carbon emission can be expressed as

$$
\begin{aligned}
& \operatorname{TEC}_{\text {Carbon }}(Q, m, r, P) \\
& =T_{x}\left[\begin{array}{l}
\left(p_{1} P^{2}-p_{2} P+p_{3}\right) D+\alpha_{b}\left[\frac{Q}{2}+r-D L+(1-b) \eta(r)\right] \\
+\alpha_{v} \frac{Q}{2}\left[m\left(1-\frac{D}{P}\right)-1+\frac{2 D}{P}\right]+\frac{2 d D}{Q}\left(a_{0}+a_{1} v+a_{2} v^{3}+\frac{a_{3}}{v^{2}}\right)
\end{array}\right] .
\end{aligned}
$$

and

$$
G\left(\frac{r-D L}{\sigma_{L}}\right)=\frac{Q\left(h_{b}+T_{x} \alpha_{b}\right)}{Q(1-b)\left(h_{b}+T_{x} \alpha_{b}\right)+\theta D+\theta_{0}(1-b) D} .
$$

From Eqs. (8) and (9), one can observe that the two decision variables $Q$ and $r$ are interdependent and it is difficult to determine the values of $Q$ and $r$ explicitly from Eqs. (8) and (9). To overcome this issue, initially we consider a 
deterministic scenario by considering $\sigma_{L}=0$, i.e., $\eta(r)=0$, and get the optimal value of $Q$ as equating it to zero. Thus, the local optimal production rate can be obtained as $P_{0}=p_{2} /\left(2 p_{1}\right)$, which minimizes pro-

$$
Q=\left[\frac{2 D\left(A+\frac{S}{m}+t_{0}\left(\frac{d}{v}\right)+2 T_{x} d\left(a_{0}+a_{1} v+a_{2} v^{3}+\frac{a_{3}}{v^{2}}\right)\right)}{h_{b}+h_{v}\left(m\left(1-\frac{D}{P}\right)-1+\frac{2 D}{P}\right)+T_{x} \alpha_{b}+T_{x} \alpha_{v}\left(m\left(1-\frac{D}{P}\right)-1+\frac{2 D}{P}\right)}\right]^{\frac{1}{2}}
$$

and the $T E C$ becomes

$$
\begin{aligned}
T C(Q, m, P)= & \frac{D}{Q}\left[A+\frac{S}{m}+t_{0} \frac{d}{v}\right] \\
& +p D+\frac{Q h_{b}}{2}+h_{v} \frac{Q}{2}\left[m\left(1-\frac{D}{P}\right)-1+\frac{2 D}{P}\right] \\
& +t_{Q}\left(\frac{d D}{v}\right) \\
& +T_{x}\left[\begin{array}{c}
\left(p_{1} P^{2}-p_{2} P+p_{3}\right) D+\alpha_{b} \frac{Q}{2} \\
+\alpha_{v} \frac{Q}{2}\left[m\left(1-\frac{D}{P}\right)-1+\frac{2 D}{P}\right] \\
+\frac{2 d D}{Q}\left(a_{0}+a_{1} v+a_{2} v^{3}+\frac{a_{3}}{v^{2}}\right)
\end{array}\right] .
\end{aligned}
$$

Putting the value of $Q$ from Eq. (10) in Eq. (11), we get

$$
\begin{aligned}
T C(m, P)= & {\left[\frac{1}{2 D}\left(A+\frac{S}{m}+2 T_{x} d D\left(a_{0}+a_{1} v+a_{2} v^{3}+\frac{a_{3}}{v^{2}}\right)+\frac{t_{0} d}{v}\right)\right.} \\
& \left.\left(h_{b}+T_{x} \alpha_{b}+\left(h_{v}+T_{x} \alpha_{v}\right)\left(m\left(1-\frac{D}{P}\right)-1+\frac{2 D}{P}\right)\right)\right]^{\frac{1}{2}} \\
& +\left[\frac{D}{2}\left(A+\frac{S}{m}+\frac{t_{0} d}{v}+2 T_{x} d D\left(a_{0}+a_{1} v+a_{2} v^{3}+\frac{a_{3}}{v^{2}}\right)\right)\right. \\
& \left.\left(h_{b}+T_{x} \alpha_{b}+\left(h_{v}+T_{x} \alpha_{v}\right)\left[m\left(1-\frac{D}{P}\right)-1+\frac{2 D}{P}\right]\right)\right]^{\frac{1}{2}} \\
& +t_{Q}\left(\frac{d D}{v}\right)+T_{x} D\left(p_{1} P^{2}-p_{2} P+p_{3}\right)+p D .
\end{aligned}
$$

One cannot obtain $P$ in the same line of $Q$ as derivative of Eq. (12) with respect to $P$ leads to a quintic equation, which cannot be solved (as per [41]).

If we consider the cost from emissions only, we can obtain the optimal production rate by differentiating the equation $\pi=p_{1} P^{2}-p_{2} P+p_{3}$ with respect to $P$ and duction-related emission. However, the rest of the SC may or may not be optimal at that point. It is assumed that there is a point $\odot$ where the rest of the SC gets minimized. Hence, the optimal value of $P$ that will minimize TEC will be either at $P_{0}$, or at $\odot$, or in between these two points. The following discussion will help in understanding the procedure to determine the mathematical value of $\odot$ and thereby the optimal range of $P$ for different values of $m$. As Eq. (12) clearly shows, the optimal value of $P$ changes with different values of $m$ [5]; we have considered different cases for $m$. While selecting the optimal range of $P$, we adhere to the fact that production rate cannot be less than the demand. Hence, the minimum possible production rate will always be $P_{\min }=\lambda D$ (where $\lambda$ is the minimum production-demand ratio, determined by management) or more than that.

Here, we discuss how the optimal ranges of $P$ change with $m$ under three different cases considering deterministic demand just to check the optimal range of $P$ and this range depends only on $m$. Hence, for random demand also, the range will remain valid.

Case A When $m=1$, Eq. (12) becomes

$$
\begin{aligned}
& T C(P)=\left[\frac { 1 } { 2 D } \left(A+S+2 T_{x} d D\left(a_{0}+a_{1} v+a_{2} v^{3}+\frac{a_{3}}{v^{2}}\right)\right.\right. \\
& \left.\left.+\frac{t_{0} d}{v}\right)\left(h_{b}+T_{x} \alpha_{b}+\left(h_{v}+T_{x} \alpha_{v}\right) \frac{D}{P}\right)\right]^{\frac{1}{2}} \\
& \quad+\left[\frac{D}{2}\left(A+S+\frac{t_{0} d}{v}+2 T_{x} d D\left(a_{0}+a_{1} v+a_{2} v^{3}+\frac{a_{3}}{v^{2}}\right)\right)\right. \\
& \left.\quad \times\left(h_{b}+T_{x} \alpha_{b}+\left(h_{v}+T_{x} \alpha_{v}\right) \frac{D}{P}\right)\right]^{\frac{1}{2}}+t_{Q}\left(\frac{d D}{v}\right) \\
& +T_{x} D\left(p_{1} P^{2}-p_{2} P+p_{3}\right)+p D .
\end{aligned}
$$

Equation (12A) shows that if we ignore emission from production, the total cost will keep on decreasing with 
increase in $P$. Hence, the cost will be minimized at a very high production rate $P_{\max }$; here $\odot=P_{\max }$. However, the cost of emission due to production would be minimized at $P_{0}=p_{2} /\left(2 p_{1}\right)$. Thus, the optimal production rate will fall within the interval $\left[P_{0}, P_{\max }\right]$ if $P_{0} \geq P_{\min }$; otherwise within $\left[P_{\min }, P_{\max }\right]$.

Case B When $m=2$, Eq. (12) becomes

$$
\begin{aligned}
& T C(P)=\left[\frac { 1 } { 2 D } \left(A+\frac{S}{2}+2 T_{x} d D\left(a_{0}+a_{1} v+a_{2} v^{3}+\frac{a_{3}}{v^{2}}\right)\right.\right. \\
& \left.\left.+\frac{t_{0} d}{v}\right)\left(h_{b}+h_{v}+T_{x}\left(\alpha_{b}+\alpha_{v}\right)\right)\right]^{\frac{1}{2}}+\left[\frac { D } { 2 } \left(A+\frac{S}{2}+\frac{t_{0} d}{v}\right.\right. \\
& \left.+2 T_{x} d D\left(a_{0}+a_{1} v+a_{2} v^{3}+\frac{a_{3}}{v^{2}}\right)\left(h_{b}+h_{v}+T_{x}\left(\alpha_{b}+\alpha_{v}\right)\right)\right]^{\frac{1}{2}} \\
& +t_{Q}\left(\frac{d D}{v}\right)+T_{x} D\left(p_{1} P^{2}-p_{2} P+p_{3}\right)+p D
\end{aligned}
$$

Equation (12B) clearly shows that for $m=2$, the optimal production rate will be $P_{o}=p_{2} /\left(2 p_{1}\right)$ if $\left(P_{o} \geq P_{\min }\right)$; otherwise it is $P_{\min }$.

Case C When $m \geq 3$, Eq. (12) becomes

$$
\begin{aligned}
T C(m, P)= & {\left[\frac{1}{2 D}\left(A+\frac{S}{m}+2 T_{x} d D\left(a_{0}+a_{1} v+a_{2} v^{3}+\frac{a_{3}}{v^{2}}\right)+\frac{t_{0} d}{v}\right)\right.} \\
& \left.\left(h_{b}+T_{x} \alpha_{b}+\left(h_{v}+T_{x} \alpha_{v}\right)\left(m\left(1-\frac{D}{P}\right)-1+\frac{2 D}{P}\right)\right)\right]^{\frac{1}{2}} \\
& +\left[\frac{D}{2}\left(A+\frac{S}{m}+\frac{t_{0} d}{v}+2 T_{x} d D\left(a_{0}+a_{1} v+a_{2} v^{3}+\frac{a_{3}}{v^{2}}\right)\right)\right. \\
& \left.\left(h_{b}+T_{x} \alpha_{b}+\left(h_{v}+T_{x} \alpha_{v}\right)\left(m\left(1-\frac{D}{P}\right)-1+\frac{2 D}{P}\right)\right)\right]^{\frac{1}{2}} \\
& +t_{Q}\left(\frac{d D}{v}\right)+T_{x} D\left(p_{1} P^{2}-p_{2} P+p_{3}\right)+p D
\end{aligned}
$$

For $m \geq 3$, the term $\left(\frac{2 D}{P}-\frac{m D}{P}\right)$ will always remain negative, but with increase in $P$ the term itself and thereby the total cost will increase. Hence, if we ignore the cost due to emission from production, the total cost will be minimized at $P_{\min }$. On the other hand, if we consider only cost of emission due to production, the minimum cost will be obtained at $P_{0}=p_{2} /\left(2 p_{1}\right)$. Hence, the total cost will be minimized at $P_{0}$ or in $\left[P_{\min }, P_{0}\right]$ when $\left(P_{0} \geq P_{\min }\right)$; otherwise it is at $P_{\min }$.

Using the optimal range of $P$, one can get the initial optimal value of $P$ using an exhaustive line search method for different cases of $m$. One can put all the possible values of $P$ (with a small step size) in Eq. (12) and select the value of $P$ as optimal where Eq. (12) is minimized. This $P$ can be used to determine the optimal $Q$ for the deterministic environment from Eq. (10). Later, this value of $Q$ will be used to determine the initial value of $r$ from Eq. (9) and then the initial $r$ in turn can be used in Eq. (8) to get the initial value of $Q$ in a random environment. Since $Q$ and $r$ are interrelated, both will converge as proposed by [42]. One can then select the $Q$ and $r$ when no further changes take place in the values of $Q$ and $r$. Again, the values of $Q$ and $r$ can be put in Eq. (7) and a line search can be conducted to get $P$. Now, this $P$ can be used again to determine $Q$ and $r$ and again a convergence test can be performed for $Q$ and $r$. Further, one can select converged values of $Q$ and $r$, and these values will be put in Eq. (12) to get the value of $P$. This iterative process will keep on going until there are no changes in all the values of of $P$, $Q$ and $r$. The values of all $P, Q$ and $r$ will converge as one will obtain $Q$ and $r$ for fixed $P$.

Till this point, we have developed the solution procedure keeping $m$ constant. Since we have shown in "Appendix A" that TEC is convex in $m$, the optimal $m$ can be calculated using the following condition: $\operatorname{TEC}\left(\mathrm{m}^{*-}\right.$ $-1) \geq \operatorname{TEC}\left(m^{*}\right) \leq \operatorname{TEC}\left(m^{*}+1\right)$. The solution procedure discussed earlier is now presented here in an algorithmic form, which has been coded in Matlab. 
Step 1: Set $m=1$, and find $P_{0}=p_{2} /\left(2 p_{1}\right)$ and $P_{\text {min }}=\lambda D$. Assume $P_{\text {max }} \rightarrow \infty$.

Step 1.1: If $P_{0}>P_{\min }$, then conduct a line search over the interval $\left[P_{0}, P_{\max }\right]$, otherwise over the interval $\left[P_{\min }, P_{\max }\right]$, to find the value of $P$ that minimizes Eq. (12).

Step 1.2: Substitute the value of $P$ in Eq. (10) to get the value of $Q$.

Step 1.3: Find $r$ by putting the value of $Q$ in Eq. (9).

Step 1.4: Put the value of $P$ and $r$ in Eq. (8) to get the revised $Q$.

Step 1.5: Repeat Steps 1.3 and 1.4 until the convergence of $Q$ and $r$ to find their value.

Step 1.6: Use $Q$ and $r$ in Eq. (7) and conduct a line search in the same interval to find the value of $P$ that minimizes Eq. (7).

Step 1.7: Substitute the value of $P$ and $r$ in Eq. (8) to get the revised $Q$.

Step 1.8: Repeat Steps 1.3 and 1.4 until the convergence of $Q$ and $r$ to find their value.

Step 1.9: Repeat Steps 1.6-1.8 until the convergence of $P, Q$ and $r$ to find their value. Select these as the optimal value of $P, Q$ and $r$ for fixed $m$.

Step 1.10: Put the value of $P, Q$ and $r$ in Eq. (7) to get $T E C\left(Q_{(m)}, r_{(m)}, m, P_{(m)}\right)$.

Step 2: Set $m=2$.

Step 2.1: The optimal $P=P_{0}=p_{2} /\left(2 p_{1}\right)$ if $\left(P_{0} \geq P_{\min }\right)$, otherwise $P_{\min }$.

Step 2.2: Perform Steps 1.2-1.5 to find the value of $Q$ and $r$.

Step 2.3: Put the value of $P, Q$ and $r$ in Eq. (7) to get $T E C\left(Q_{(m)}, r_{(m)}, m, P_{(m)}\right)$.

Step 3: If $\operatorname{TEC}\left(Q_{(m)}, r_{(m)}, m, P\right) \leq \operatorname{TEC}\left(Q_{(m-1)}, r_{(m-1)}, m-1, P\right)$ go to Step 4; otherwise go to Step 5 .

Step 4: Set $m=m+1$, and then conduct a line search over the interval $\left[P_{\min }, P_{0}\right]$ to find the value of $P$ that minimizes Eq. (12). Perform Steps $1.2-1.10$ to get $\operatorname{TEC}\left(Q_{(m)}, r_{(m)}, P_{(m)}, m\right)$, and go to Step 3.

Step 5: Set $T E C(Q, r, m, P)=T E C\left(Q_{(m-1)}, r_{(m-1)}, m-1, P\right)$, then $(Q, r, m, P)$ is the optimal solution.

Step 6: Put the optimal $Q, r, m, P$ in Eqs. (5) and (7) to get TEE and TEC, respectively.

Using this stepwise procedure, the optimal production rate, order quantity, reorder point and number of shipments per production cycle can be obtained. In figure 2 we have presented a flowchart to explain the algorithm for a better understanding of the solution procedure. In the next section, we illustrate the model through a numerical study and examine the impact of some key parameters.

\section{Numerical examples and sensitivity analysis}

In this section, we present numerical examples to illustrate the model. Most of the parameters used in the numerical examples are taken from published articles. To illustrate the proposed models and solution procedures, a two-stage SC is considered with the following data. The secondary data are taken from published articles [23, 43-45] $D=600$ units/ year, $\quad A=\$ 200 /$ order, $\quad S=\$ 1500 /$ set-up, $\quad \theta=\$ 50 /$ unit, $\theta_{0}=\$ 65 /$ unit $, d=1000 \mathrm{~km}, v=50 \mathrm{~km} / \mathrm{h}, p=\$ 100 /$ unit, $h_{b}=\$ 5 /$ unit/year, $h_{v}=\$ 2 /$ unit/year, $t_{0}=\$ 10 / \mathrm{h}, t_{Q}=\$ 5 /$ unit/h, $p_{1}=3 \times 10^{-7}$ ton $\cdot$ year $^{2} /$ unit $^{3}, p_{2}=0.0012$ ton $\cdot$ year/unit ${ }^{2}, p_{3}=1.4$ tonne/unit, $\alpha_{b}=0.08$ tonne/unit/year, $\alpha_{v}=0.08$ tonne/unit/year, $\lambda=1.5, \quad \sigma=1$ unit/day, $L=1$ week, $b=0.60, T_{x}=\$ 32 /$ tonne.

Now, using the proposed solution procedure, we can determine the optimal value of $P, Q, r$ and $m$. Subsequently, the corresponding values of TEC and TEE will be found by putting the optimal value of decision variables in Eqs. (5) and (7), respectively. For the base case, we get $P^{*}=2000$ unit, $m^{*}=2, Q^{*}=346.07$ unit, $r^{*}=15.71$ unit, TEC $=\$$ 188066.33 and $T E E=150.99$ tonne. Next, sensitivity analysis is carried out with respect to key parameters to draw certain good managerial insights. During sensitivity analysis we have considered only those parameters that 

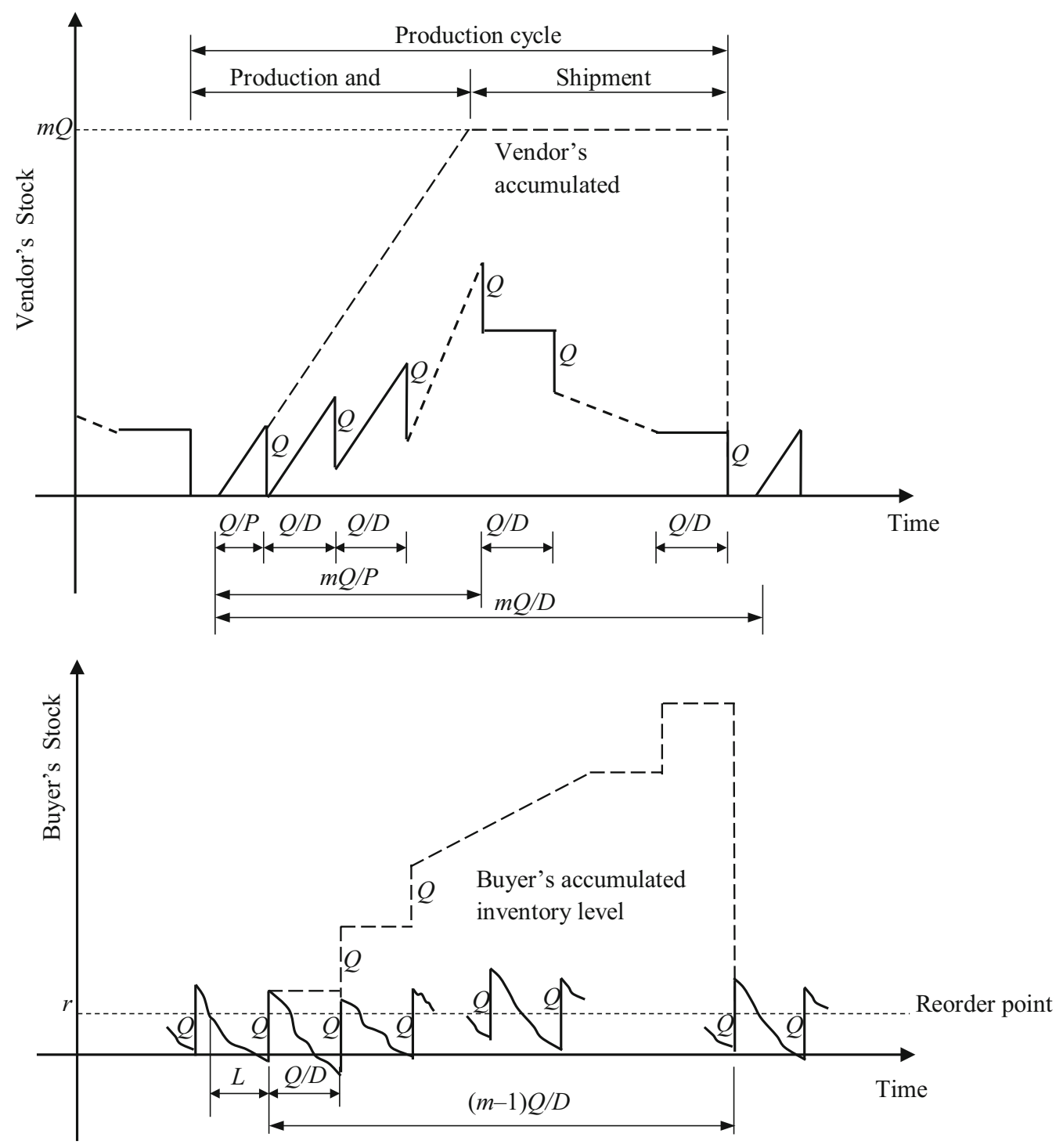

Figure 1. The inventory pattern for the vendor and the buyer.

have some considerable impact on TEC and TEE. We have further discussed how these parameters impact TEC and $T E E$ with analytical illustrations, which may help readers to draw managerial insights.

\subsection{Effects of $v$ on TEC and TEE}

Figure 3 indicates that as the value of $v$ increases TEC decreases; on the other hand, TEE initially goes down, then after an instantaneous increase in value, it shows a convex nature. The reasons behind the changing pattern of TEC and $T E E$ are explained here. If we consider $v$ in isolation, i.e., apart from any decision variable, it is evident that both $T E C$ and TEE would be convex in $v$, as the cost due to transportation $t_{0}\left(\frac{d D}{v Q}\right)+t_{Q}\left(\frac{d D}{v}\right)$ is clearly convex in $v$ and the emission due to transportation is also convex in $v$ (see [38]). However, clearly neither TEC nor TEE exhibits convexity in $v$ here, as these terms and as a whole both TEC and TEE depend on other decision variables. The change of different decision variables and corresponding changes in TEC and $T E E$ are presented in table 3 and further discussed.

From table 3 , one can see that with increasing $v$, there is a continuous decrease in $Q$; reduction in $Q$ leads to decrease in the cost of inventory holding at both the buyer, i.e. $h_{b}\left[\frac{Q}{2}+r-D L+(1-b) \eta(r)\right]$, and at the vendor, i.e. $h_{v} \frac{Q}{2}\left[m\left(1-\frac{D}{P}\right)-1+\frac{2 D}{P}\right]$; it also reduces emission-related cost due to inventory holding $T_{x}\left(\alpha_{b}\left[\frac{Q}{2}+r-D L+(1-b)\right.\right.$ $\left.\eta(r)]+\alpha_{v} \frac{Q}{2}\left[m\left(1-\frac{D}{P}\right)-1+\frac{2 D}{P}\right]\right)$ and an increasing $v$ also helps reduce both transportation-related cost and emissionrelated cost from transportation (due to convexity of $T E C$ 


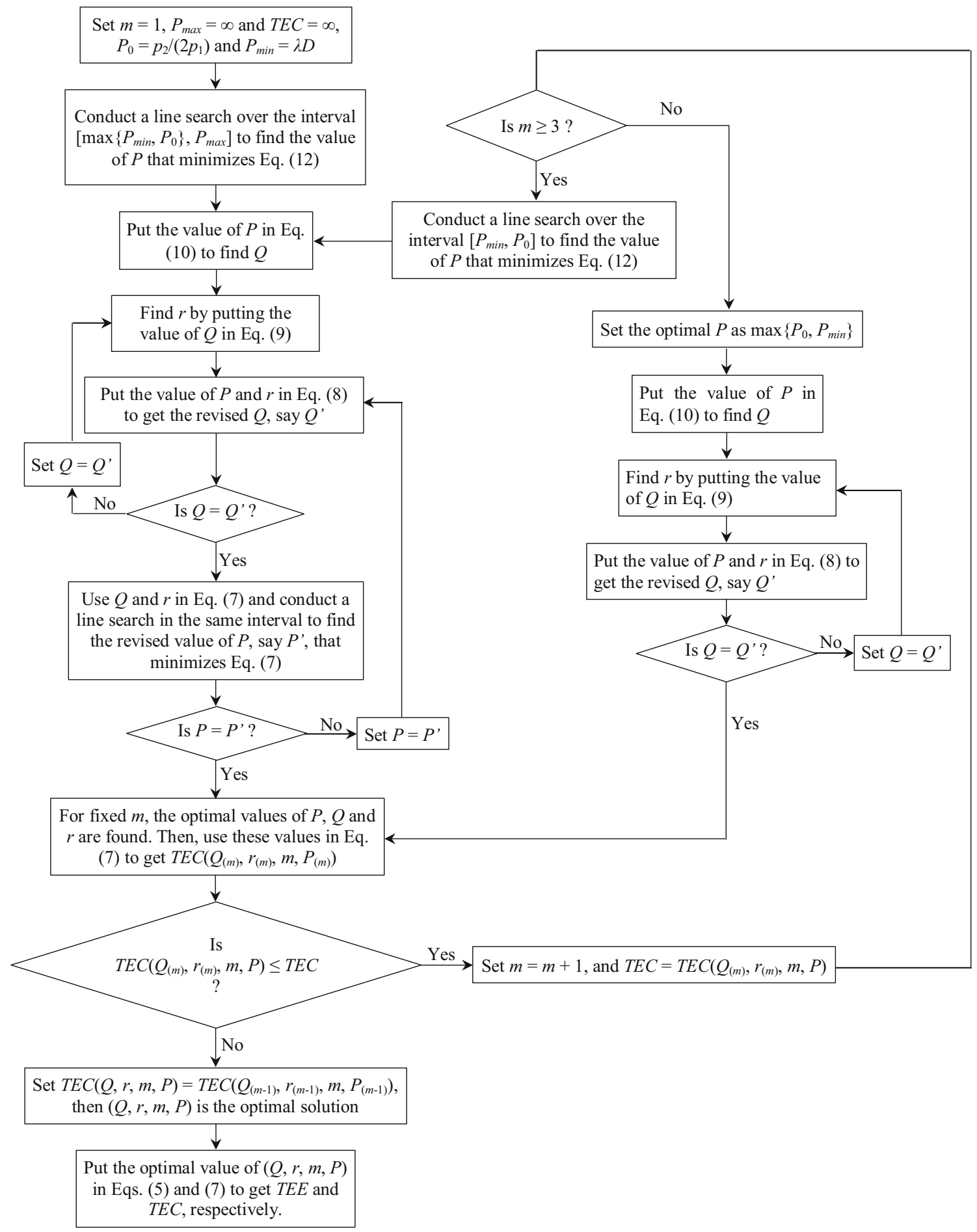

Figure 2. Flowchart of proposed algorithm.

and TEE in $v$ both will keep on decreasing up to a certain point, as discussed earlier) and all these reductions in cost parameters significantly reduce $T E C$. Reduction in TEE is also an outcome of major reduction in emissions due to inventory holding and transportation. However, we observe a sudden increase in TEE that takes place when $m$ increases, since, with increase in $m$, the production lot size $m Q$ certainly increases, which leads to increase in the inventory level at the vendor and corresponding emission. We also observe that increase in $m$ leads to a sharp decline in $Q$, which rises the emission related to transportation $\frac{2 d D}{Q}\left(a_{0}+a_{1} v+a_{2} v^{3}+\frac{a_{3}}{v^{2}}\right)$ to some extent; rise in emission 


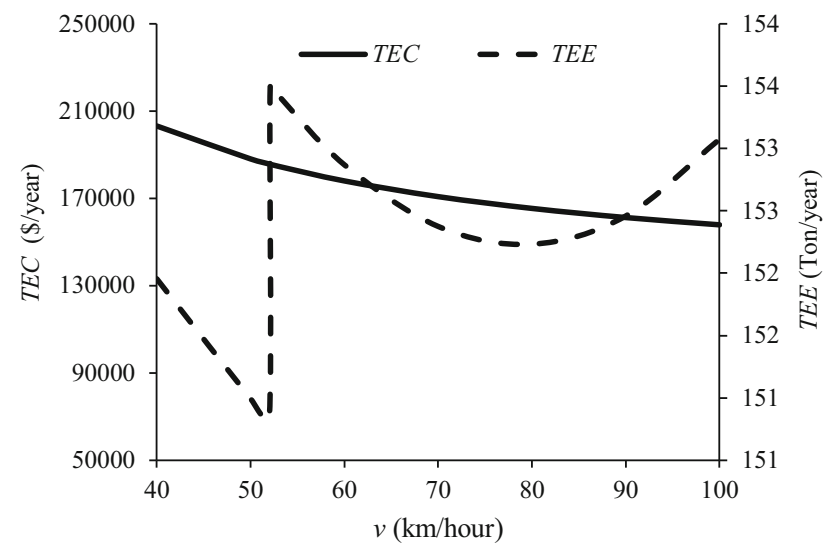

Figure 3. Effect of $v$ on TEC and TEE.

Table 3. Change in decision variables and in $T E C$ and $T E E$ with changing $v$.

\begin{tabular}{lcccccc}
\hline$v$ & $Q$ & $r$ & $P$ & $m$ & TEC & TEE \\
\hline 40 & 354.18 & 15.68 & 2000.00 & 2 & 203164.37 & 151.95 \\
50 & 346.07 & 15.71 & 2000.00 & 2 & 188066.33 & 150.99 \\
60 & 268.62 & 16.03 & 1991.96 & 3 & 177986.26 & 152.87 \\
70 & 264.83 & 16.05 & 1992.08 & 3 & 170785.52 & 152.37 \\
80 & 262.35 & 16.06 & 1992.15 & 3 & 165390.64 & 152.23 \\
90 & 261.01 & 16.06 & 1992.19 & 3 & 161203.38 & 152.46 \\
100 & 260.68 & 16.06 & 1992.20 & 3 & 157865.13 & 153.07 \\
\hline
\end{tabular}

from those two areas leads to an overall increase in $T E E$, though the emission from the inventory at the buyer $\alpha_{b}\left[\frac{Q}{2}+r-D L+(1-b) \eta(r)\right]$ reduces. Increase in production lot size $m Q$ with increase in $m$ also leads to increase in inventory holding cost at the vendor $h_{v} \frac{Q}{2}\left[m\left(1-\frac{D}{P}\right)-1+\frac{2 D}{P}\right]$ and corresponding emission-related cost. In spite of the increase in certain cost parameters, the $T E C$ decreases even with increase in $m$ mainly due to sharp reduction in set-up cost, i.e. $\frac{S D}{m Q}$.

Since we observe a sudden change in TEE, we depict here the changing pattern of emissions from different sources in figure 4 . The reason behind the changing pattern of emission from inventory and transportation has already been discussed. It is observed that though some changes take place in the production rate, the changes in the emission due to production rate is very negligible as the first two terms of $\left(p_{1} P^{2}-p_{2} P+p_{3}\right)$ almost balance each other.

Since, both TEC and TEE can be reduced to a great extent by controlling $v$, finding ideal value of $v$ is an important aspect for managers. In our example, the value of $T E E$ gets minimized at the velocity of $52 \mathrm{~km} / \mathrm{h}$. Now, if someone increases the velocity further to reduce TEC, TEE increases sharply. If someone increases $v$ slightly and makes it $52.1 \mathrm{~km} / \mathrm{h}$, the cost reduces by $0.06 \%$, but the emission increases by $1.8 \%$ and also that is the maximum

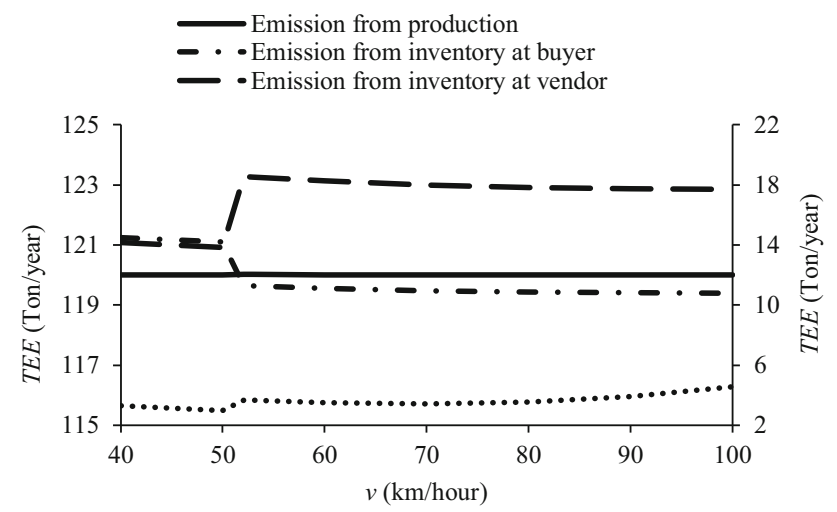

Figure 4. Effect of $v$ on emissions from different sources.

for the given range for $v$, but again a further increase in $v$ will reduce both TEC and TEE. Hence, managers are supposed to determine a velocity where firms will be benefited from both economic as well as environmental point of view.

\subsection{Effects of $T_{x}$ on TEC and TEE}

Figure 5 depicts the changing pattern of TEC and TEE with changing $T_{x}$. Determination of viable $T_{x}$ is a very important aspect for regulatory bodies. It is found that with increasing $T_{x}$, there is a steady increase in $T E C$. The rate of change in $T E E$ is initially steeper compared with the changing rate of $T E E$ with increasing $T_{x}$. The change in TEC can be explained easily. If we consider $T E C$, one can observe the linear relationship between $T E C$ and $T_{x}$ with the expression for emission-related cost, i.e.

$$
\begin{aligned}
& T_{x}\left(\left(p_{1} P^{2}-p_{2} P+p_{3}\right) D+\alpha_{b}\left[\frac{Q}{2}+r-D L+(1-b) \eta(r)\right]\right. \\
& \quad+\alpha_{v} \frac{Q}{2}\left[m\left(1-\frac{D}{P}\right)-1+\frac{2 D}{P}\right] \\
& \left.\quad+\frac{2 d D}{Q}\left(a_{0}+a_{1} v+a_{2} v^{3}+\frac{a_{3}}{v^{2}}\right)\right)
\end{aligned}
$$

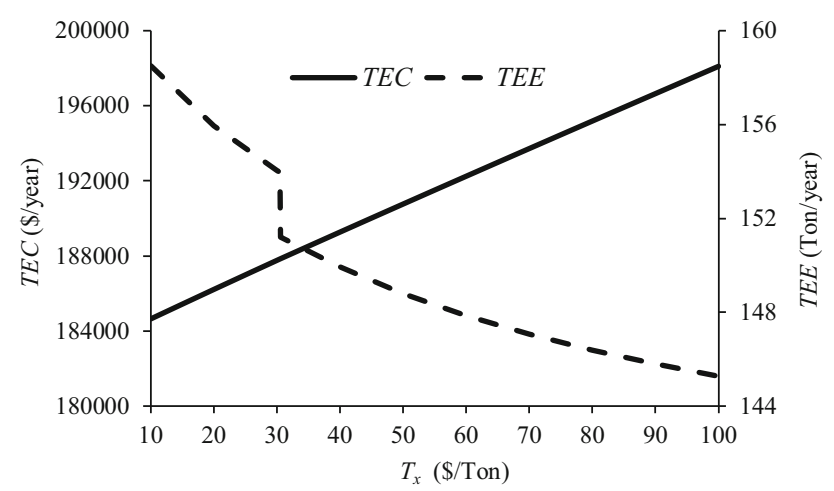

Figure 5. Effect of $T_{x}$ on TEC and TEE. 
Hence, due to the predominant value of $T_{x}, T E C$ changes almost linearly with the change in $T_{x}$ irrespective of variations in decision variables. Though, because of high rate of change in $T_{x}$, the emission-related cost and subsequently TEC change linearly with $T_{x}$, the TEE does not vary linearly. The changing pattern of TEE and different emission parameters is discussed later. One can see from the equation

$$
\begin{aligned}
T E E(Q, m, r, P)= & \left(p_{1} P^{2}-p_{2} P+p_{3}\right) D \\
& +\alpha_{b}\left[\frac{Q}{2}+r-D L+(1-b) \eta(r)\right] \\
& +\alpha_{v} \frac{Q}{2}\left[m\left(1-\frac{D}{P}\right)-1+\frac{2 D}{P}\right] \\
& +\frac{2 d D}{Q}\left(a_{0}+a_{1} v+a_{2} v^{3}+\frac{a_{3}}{v^{2}}\right)
\end{aligned}
$$

that TEE does not have any direct relation with $T_{x}$, but as $T_{x}$ increases to optimize $T E C$, the values of the decision variables change and that leads to change in TEE.

From table 4 , one can see that when $T_{x}$ increases, initially the value of $m$ remains unchanged but $Q$ keeps on decreasing significantly, which leads to inventory-related emission at the buyer end, i.e. $\alpha_{b}\left[\frac{Q}{2}+r-D L+(1-b) \eta(r)\right]$ and the vendor $\alpha_{v} \frac{Q}{2}\left[m\left(1-\frac{D}{P}\right)-1+\frac{2 D}{P}\right]$. After a certain interval, the number of shipments $m$ also reduces and that causes a huge reduction in production lot size $m Q$ and thereby emission due to inventory at the vendor. After this sudden change, when the $m$ remains unchanged, the TEE keeps on decreasing, but the decrease rate reduces as the changing rate of $Q$ decreases. In figure 6, we have shown change of emissions from different sources.

These observations reveal that with increasing $T_{x}$ the total cost gets increased to a great extent, but that does not get reflected if we consider a reduction in emission. Hence, regulatory bodies should try to find an effective tax rate that will considerably reduce emission without hiking the total cost much.

Table 4. Change in decision variables and in TEC and TEE with changing $T_{x}$.

\begin{tabular}{lcccccc}
\hline$T_{x}$ & $P$ & $Q$ & $r$ & $m$ & TEC & $T E E$ \\
\hline 10 & 1980.76 & 323.53 & 16.12 & 3 & 184641.43 & 158.52 \\
20 & 1988.72 & 297.50 & 16.07 & 3 & 186213.10 & 155.95 \\
30 & 1991.45 & 277.58 & 16.01 & 3 & 187762.67 & 154.04 \\
40 & 2000.00 & 331.01 & 15.66 & 2 & 189269.87 & 149.92 \\
50 & 2000.00 & 315.08 & 15.61 & 2 & 190763.29 & 148.80 \\
60 & 2000.00 & 301.60 & 15.55 & 2 & 192246.46 & 147.86 \\
70 & 2000.00 & 290.02 & 15.50 & 2 & 193721.01 & 147.07 \\
80 & 2000.00 & 279.95 & 15.45 & 2 & 195188.19 & 146.39 \\
90 & 2000.00 & 271.08 & 15.40 & 2 & 196649.01 & 145.79 \\
100 & 2000.00 & 263.21 & 15.36 & 2 & 198104.29 & 145.27 \\
\hline
\end{tabular}

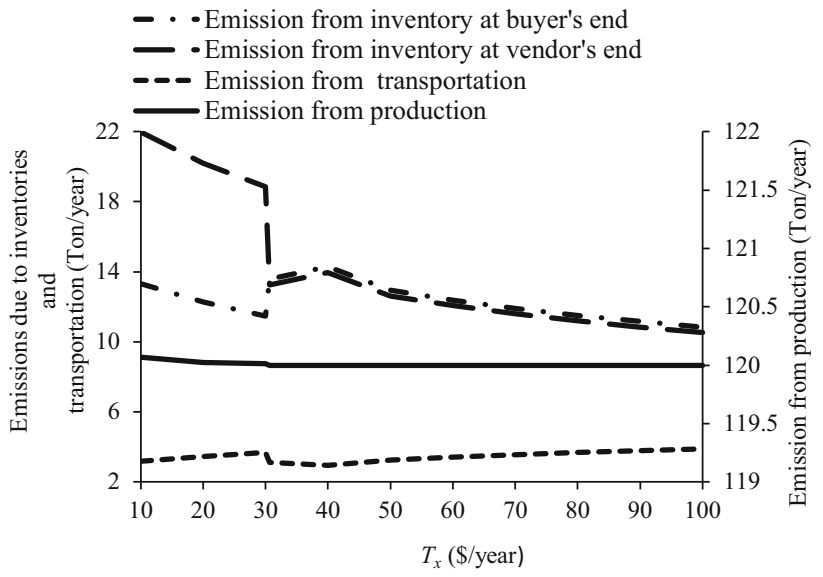

Figure 6. Effect of $T_{x}$ on emissions from different sources.

\subsection{Effects of $\lambda$ on TEC and TEE}

Figure 7 shows that with changing $\lambda$, initially there is no change in TEC and TEE, but after a certain threshold level of $\lambda$, both TEC and TEE increase. The reasons behind these changing patterns of $T E C$ and $T E E$ can be explained with table 5.

Table 5 explains a very interesting aspect that with changing $\lambda$ only production rate $P$ changes and other decision variables remain unchanged. Here, one gets the optimal number of shipments $m=2$. Earlier we have shown that at $m=2$, optimal production rate will be $P_{0}=p_{2} /\left(2 p_{1}\right)$ if $\left(P_{0} \geq P_{\text {min }}\right)$; otherwise it is $P_{\text {min }}$. Now, with the existing parameters and $P_{0}=2000, P_{\text {min }}$ varies with $\lambda$ as $P_{\min }=\lambda D$. Hence, the production rate $P$ remains at 2000 as long as $P_{0} \geq \lambda D$. Due to an increase in $\lambda D$, for any value more than $P_{0}=2000$, the production rate $P$ always takes value of $\lambda D$ as that is the minimum permissible production rate $P_{\min }$. Now, one interesting thing is that if one considers total cost as a summation of three different cost elements - cost incurred by the buyer $\left(T E C_{b}\right)$, cost

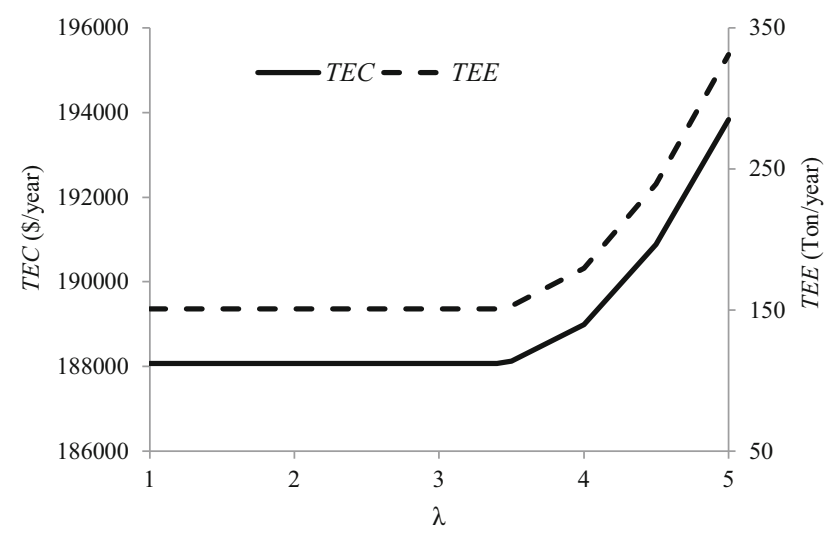

Figure 7. Effect of $\lambda$ on TEC and TEE. 
Table 5. Change in decision variables and in TEC and TEE with changing $\lambda$.

\begin{tabular}{lcccccc}
\hline$\lambda$ & $P$ & $Q$ & $r$ & $m$ & TEC & TEE \\
\hline 1.00 & 2000 & 346.07 & 15.71 & 2 & 188066.33 & 150.99 \\
1.50 & 2000 & 346.07 & 15.71 & 2 & 188066.33 & 150.99 \\
2.00 & 2000 & 346.07 & 15.71 & 2 & 188066.33 & 150.99 \\
2.50 & 2000 & 346.07 & 15.71 & 2 & 188066.33 & 150.99 \\
3.00 & 2000 & 346.07 & 15.71 & 2 & 188066.33 & 150.99 \\
3.50 & 2100 & 346.07 & 15.71 & 2 & 188987.93 & 152.79 \\
4.00 & 2400 & 346.07 & 15.71 & 2 & 190888.73 & 179.79 \\
4.50 & 2700 & 346.07 & 15.71 & 2 & 193826.33 & 239.19 \\
5.00 & 3000 & 346.07 & 15.71 & 2 & 190888.73 & 330.99 \\
\hline
\end{tabular}

incurred by the vendor $\left(T E C_{v}\right)$ and cost due to carbon emission $\left(T E C_{\text {emission }}\right)$, there is no change in $T E C_{b}$ and $T E C_{v}$; only $T E C_{\text {emission }}$ changes. The pattern of these three costs parameters with changing $\lambda$ is shown in figure 8 .

This finding is in line with our earlier discussion of Eq. (12B), where we have shown that at $m=2$, production rate $P$ plays no role in determining any cost parameter except cost due to emission from production. If this situation arrives then managers have an important role to play. Since the cost at the vendor is not affected with production rate at $m=2$, they can go for any production rate within the given capacity of the production system but that may increase the total SC cost. Hence, managers should clearly communicate and inspect the production rate at the vendor. However, the scenario will be different when $m=1$ or $m>2$, as discussed earlier.

\subsection{Effects of $L$ on TEC and TEE}

Figure 9 shows that with increasing $L$, both TEC and TEE increase. Physically, this phenomenon can be explained very clearly; increasing lead time pushes the buyer to keep higher reorder point $r$ and that is why the inventory at the

\section{- Cost incured by vendor - Cost incured by buyer Cost due to emission}

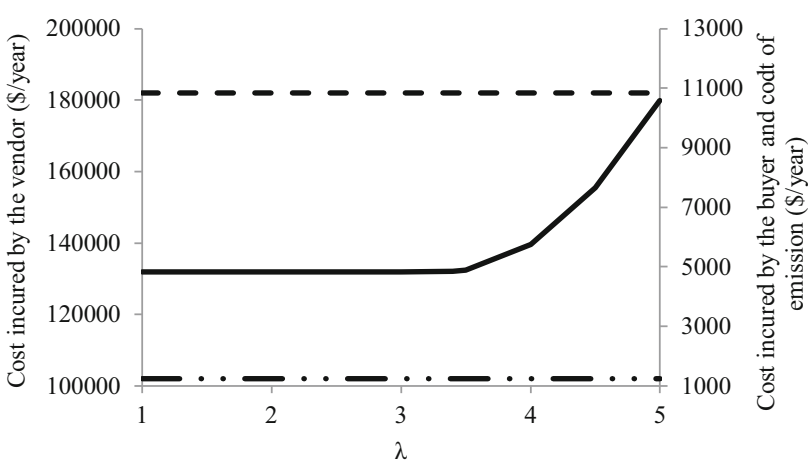

Figure 8. Effect of $\lambda$ on different costs.

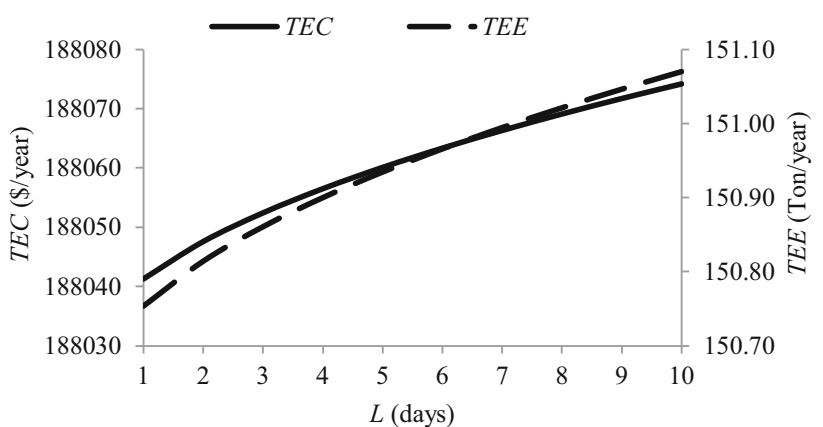

Figure 9. Effect of $L$ on TEC and TEE.

Table 6. Change in decision variables and in TEC and TEE with changing $L$.

\begin{tabular}{lcccccc}
\hline$L$ & $P$ & $Q$ & $r$ & $m$ & TEC & $T E E$ \\
\hline 1 & 2000 & 345.64 & 3.23 & 2 & 188041.28 & 150.75 \\
2 & 2000 & 345.75 & 5.53 & 2 & 188047.59 & 150.81 \\
3 & 2000 & 345.83 & 7.68 & 2 & 188052.42 & 150.86 \\
4 & 2000 & 345.90 & 9.75 & 2 & 188056.50 & 150.90 \\
5 & 2000 & 345.96 & 11.77 & 2 & 188060.09 & 150.93 \\
6 & 2000 & 346.02 & 13.75 & 2 & 188063.34 & 150.97 \\
7 & 2000 & 346.07 & 15.71 & 2 & 188066.33 & 150.99 \\
8 & 2000 & 346.12 & 17.64 & 2 & 188069.10 & 151.02 \\
9 & 2000 & 346.16 & 19.56 & 2 & 188071.71 & 151.05 \\
10 & 2000 & 346.21 & 21.46 & 2 & 188074.18 & 151.07 \\
\hline
\end{tabular}

buyer $h_{b}\left[\frac{Q}{2}+r-D L+(1-b) \eta(r)\right]$ increases; simultaneously the corresponding emission-related cost $T_{x} \alpha_{b}\left[\frac{Q}{2}+r-D L+(1-b) \eta(r)\right]$ also increases. The change of decision variables with $L$ is shown in table 6 .

From table 6, it is clear that with increasing $L$ the reorder point $r$ significantly increases and that leads to higher average inventory level at the buyer. When $r$ increases the value of expected demand shortage $\eta(r)$ at the end of each cycle of the buyer also increases; hence the cost of backorders and lost sales also increase. Loss can takes place in terms of intangible aspects such as loss of customers' loyalty and brand value of organizations. From the earlier discussion, we can conclude that controlling lead time is an important aspect to reduce both cost and emission. Managers can consider investing for improving the production and operational areas to reduce the lead time.

\section{Conclusions}

In this study, a two-echelon SC comprising a single vendor and a single buyer is considered. We have emissions from all the major sources, namely production, inventory and 
transportation in an SC. The TEC of the SC is minimized by simultaneously optimizing the production rate, ordering quantity, reorder point and the number of shipments from the vendor to the buyer in a production cycle with random demand under carbon tax policy. We have shown that with some operational adjustments of the parameters, both the cost and emission can be controlled.

This model will help organizations to determine optimal production rate, order quantity, reorder point and number of shipments. Sensitivity analysis has revealed that organizations can reduce both TEC and total expected emission simultaneously by operational adjustments. Our study shows that with increasing $v$, the TEC reduces all the way, but it may increase the TEE. The production rate $P$ is also a very important aspect, which can be used effectively to reduce both TEC and TEE. Reduction of $L$ always helps to reduce $T E C$ and $T E E$. Further, $T_{x}$ can be used efficiently to reduce $T E E$ without affecting $T E E$ much.

Opportunity for future extension of this work is numerous. We have considered a two-echelon serial SC; a more complex model with multi-echelon or reverse SC can be further studied. A future study can consider a finite planning horizon with or without perishable products. Different
$\operatorname{TEC}(Q, m, r, P)$ is positive definite at point $(Q, r)$ for fixed $m$ and $P$.

We first get the Hessian matrix $\mathrm{H}$ as follows:

$$
\mathrm{H}=\left[\begin{array}{ll}
\frac{\partial^{2} T E C(\cdot)}{\partial Q^{2}} & \frac{\partial^{2} T E C(\cdot)}{\partial Q \partial r} \\
\frac{\partial^{2} T E C(\cdot)}{\partial r \partial Q} & \frac{\partial^{2} T E C(\cdot)}{\partial r^{2}}
\end{array}\right],
$$$$
\text { Where } \operatorname{TEC}(\cdot)=\operatorname{TEC}(Q, r) \text {. }
$$

where $\operatorname{TEC}(\cdot)=\operatorname{TEC}(Q, r)$.

The first principal determinant of $\mathrm{H}$

$$
\begin{aligned}
& \frac{\partial^{2} T E C(\cdot)}{\partial Q^{2}}=\frac{2 D}{Q^{3}}\left[A+\frac{S}{m}+\frac{t_{0} d}{v}+\theta \eta(r)+\theta_{0}(1-b) \eta(r)\right. \\
& \left.+2 d T_{x}\left(a_{0}+a_{1} v+a_{2} v^{3}+\frac{a^{3}}{v^{2}}\right)\right]>0
\end{aligned}
$$

and

$$
\frac{\partial^{2} T E C(\cdot)}{\partial r^{2}}=\left[\left(h_{b}+T_{x} \alpha_{b}\right)(1-b)+\frac{D}{Q}\left(\theta+\theta_{0}(1-b)\right)\right] f\left(\frac{r-D L}{\sigma_{L}}\right)>0 .
$$

The second principal determinant of $\mathrm{H}$ is

$$
\begin{aligned}
& \left|H_{22}\right|=\frac{\partial^{2} T E C(\cdot)}{\partial Q^{2}} \times \frac{\partial^{2} T E C(\cdot)}{\partial r^{2}}-\frac{\partial^{2} T E C(\cdot)}{\partial Q \partial r} \times \frac{\partial^{2} T E C(\cdot)}{\partial r \partial Q} . \\
& \frac{\partial^{2} T C(\cdot)}{\partial Q^{2}} \times \frac{\partial^{2} T C(\cdot)}{\partial r^{2}}-\frac{\partial^{2} T C(\cdot)}{\partial Q \partial r} \times \frac{\partial^{2} T C(\cdot)}{\partial r \partial Q} \\
& =\frac{2 D}{Q^{3}} f\left(\frac{r-D L}{\sigma_{L}}\right)\left[\begin{array}{l}
\left(A+\frac{S}{m}+2 d\left(a_{0}+a_{1} v+a_{2} v^{3}+\frac{a_{3}}{v^{2}}\right)\right)\left(\left(h_{b}+T_{x} \alpha_{b}\right)(1-b)+\frac{D}{Q}\left(\theta+\theta_{0}(1-b)\right)\right) \\
+\left(h_{b}+T_{x} \alpha_{b}\right)(1-b)\left(\theta+\theta_{0}(1-b)\right) \eta(r)
\end{array}\right] \\
& +\frac{D^{2}}{Q^{4}}\left(\theta+\theta_{0}(1-b)\right)^{2}\left[2 \eta(r) f\left(\frac{r-D L}{\sigma_{L}}\right)-\left(G\left(\frac{r-D L}{\sigma_{L}}\right)\right)^{2}\right]>0 .
\end{aligned}
$$

other aspects like machine breakdown, production of defective items and sorting can also be considered. One obvious extension of this problem can be done with consideration of other carbon policies or proposing a hybrid carbon policy.

\section{Appendix A}

\section{Proof of convexity of TEC in $Q$ and $r$}

To prove the convexity of $\operatorname{TEC}(Q, m, r, P)$ with respect to $Q$ and $r$, we need to show that the Hessian matrix of since $2 \eta(r) f\left(\frac{r-D L}{\sigma_{L}}\right)-\left(G\left(\frac{r-D L}{\sigma_{L}}\right)\right)^{2}>0$ for $\eta(r)>0$ and $f\left(\frac{r-D L}{\sigma_{L}}\right)>0$ (see [43]).

Hence, $\operatorname{TEC}(Q, r)$ is convex in $Q$ and $r$.

\section{Proof of convexity of $m$}

In order to check the convexity of $\operatorname{TEC}(Q, r, m, P)$ with respect to $m$, we temporarily relax the integrality requirement on $m$ and take the first and second derivatives of $T E C(Q, r, m, P)$ with respect to $m$ for fixed $(Q, r, P)$ and get 


$$
\frac{\partial T E C(m)}{\partial m}=-\frac{S D}{m^{2} Q}+\left[h_{v}+T_{x} \alpha_{v}\right] \frac{Q}{2}\left(1-\frac{D}{P}\right)
$$

and

$$
\frac{\partial^{2} T E C(m)}{\partial m^{2}}=\frac{2 S D}{m^{3} Q}>0 .
$$

Hence, $\operatorname{TEC}(m)$ is convex in $m$.

\section{References}

[1] World Health Organization 2016 Climate change and health. http://www.who.int/mediacentre/factsheets/fs266/en/, available on 18.08.2016

[2] Du S, Hu L and Wang L 2017 Low-carbon supply policies and supply chain performance with carbon concerned demand. Ann. Oper. Res. 255(1-2): 569-590

[3] Kinaxis 2009 Providing carbon footprint visibility and planning capabilities across the supply chain. In: Supply chain expert series, http://www.kinaxis.com/downloads/register/ WP-Carbon_Footprint_Planning_Capabilities.pdf. Accessed 28 Dec 2012

[4] Fareeduddin M, Hassan A, Syed M N and Selim S Z 2015 The impact of carbon policies on closed-loop supply chain network design. Procedia CIRP 26: 335-340

[5] Jaber M Y, Glock C H and El Saadany A M A 2013 Supply chain coordination with emissions reduction incentives. Int. J. Prod. Res. 51(1): 69-82

[6] Metcalf G E 2009 Market-based policy options to control U.S. greenhouse gas emissions. J. Econ. Perspect. 23(2): 5-27

[7] Kaufman N 2016 Carbon tax vs. cap-and-trade: what's a better policy to cut emissions? World Resources Institute, http:// www.wri.org/blog/2016/03/carbon-tax-vs-cap-and-tradewhat's-better-policy-cut-emissions, available on 04.08.2016

[8] Chen X, Benjaafar S and Elomri A 2013 The carbon-constrained EOQ. Oper. Res. Lett. 41(2): 172-179

[9] Srivastava S K and Srivastava R K 2006 Managing product returns for reverse logistics. Int. J. Phys. Distrib. Logist. Manag. 36(7): 524-546

[10] Srivastava S K 2007 Green supply-chain management: a stateof-the-art literature review. Int. J. Manag. Rev. 9(1): 53-80

[11] Darnall N, Jolley G J and Handfield R 2008 Environmental management systems and green supply chain management: complements for sustainability? Bus. Strateg. Environ. 45(18): $30-45$

[12] Ciliberti F, Pontrandolfo P and Scozzi B 2008 Logistics social responsibility: standard adoption and practices in Italian companies. Int. J. Prod. Econ. 113(1): 88-106

[13] Walmart. Beyond 50 years: building a sustainable future. 2012. Global Responsibility Report, Walmart, USA, available from http://c46b2bcc0db5865f5a76-91c2ff8eba65983a1 c33d367b8503d02.r78.cf2.rackcdn.com/d3/35/66be9cc44c2b 8d096565166e79f4/2012-global-responsibility-report_12982 3695403288526.pdf 2016, accessed on 28.04.16

[14] Business in the community 2015 How Tesco is building its sustainability strategy through its supply chain. Business in the community, April 9, available from http://www.bitc.org. uk/blog/post/how-tesco-building-its-sustainability-strategythrough-its-supply-chain 2016, accessed 28.04.16

[15] Beavis L 2015 Unilever: design once, deploy everywhere. The Guardian, April 20, available from http://www.the guardian.com/sustainable-business/2015/apr/30/unileverdesign-once-deploy-everywhere 2016, accessed 28.04.16

[16] Labatt S and White R R 2007. Carbon finance. New Jersey: Wiley Finance

[17] Fahimnia B, Sarkis J, Dehghanian F, Banihashemi N and Rahman S 2013 The impact of carbon pricing on a closed-loop supply chain: an Australian case study. J. Clean. Prod. 59: 210-225

[18] Yuyin Y and Jinxi L 2018 The effect of governmental policies of carbon taxes an energy-saving subsidies on enterprise decisions in a two-echelon supply chain. J. Clean. Prod. 181: 675-691

[19] Dobos I 2005 The effects of emission trading on production and inventories in the Arrow-Karlin model. Int. J. Prod. Econ. 93-94: 301-308

[20] Dobos I 2007 Tradable permits and production-inventory strategies of the firm. Int. J. Prod. Econ. 108(1-2): 329-333

[21] Diabat A and Simchi-Levi D 2009 A carbon-capped supply chain network problem. In: Proceedings of the IEEE International Conference on Industrial Engineering and Engineering Management, pp. 532-527

[22] Hua G, Cheng T C E and Wang S 2011 Managing carbon footprints in inventory management. Int. J. Prod. Econ. 132(2): 178-185

[23] Wahab M I M, Mamun S M H and Ongkunaruk P 2011 EOQ models for a coordinated two-level international supply chain considering imperfect items and environmental impact. Int. J. Prod. Econ. 134(1): 151-158

[24] Abdallah T, Farhat A, Diabat A and Kennedy S 2012 Green supply chains with carbon trading and environmental sourcing: formulation and life cycle assessment. Appl. Math. Model. 36(9): 4271-4285

[25] Bouchery Y, Ghaffari A, Jemai Z and Dallery Y 2012 Including sustainability criteria into inventory models. Eur. J. Oper. Res. 222(2): 229-240

[26] Benjaafar S, Li Y and Daskin M 2013 Carbon footprint and the management of supply chains: insights from simple models. IEEE Trans. Autom. Sci. Eng. 10(1): 99-116

[27] Toptal A, Özlü H and Konur D 2014 Joint decisions on inventory replenishment and emission reduction investment under different emission regulations. Int. J. Prod. Res. 52(1): 243-269

[28] Hammami R, Nouira I and Frein Y 2015 Carbon emissions in a multi-echelon production-inventory model with lead time constraints. Int. J. Prod. Econ. 164: 292-307

[29] Neale J J and Willems S P 2009 Managing inventory in supply chains with nonstationary demand. Interfaces 39(5): 388-399

[30] Rosič H and Jammernegg W 2013 The economic and environmental performance of dual sourcing: a newsvendor approach. Int. J. Prod. Econ. 143(1): 109-119

[31] Zhang B and Xu L 2013 Multi-item production planning with carbon cap and trade mechanism. Int. J. Prod. Econ. 144(1): 118-127

[32] Arikan E and Jammernegg W 2014 The single period inventory model under dual sourcing and product carbon footprint constraint. Int. J. Prod. Econ. 157: 15-23

[33] Dong C, Shen B, Chow P S, Yang L and Ng C T 2016 Sustainability investment under cap-and-trade regulation. Ann. Oper. Res. 240(2): 509-531 
[34] Purohit K A, Shankar R, Dey P K and Choudhary A 2016 Non-stationary stochastic inventory lot-sizing with emission and service level constraints in a carbon cap-andtrade system. J. Clean. Prod. 113: 654-661

[35] Axsäter S 2015 Inventory control, vol. 225. Springer Science \& Business Media, Springer, New York

[36] Montgomery D C, Bazaraa M S and Keswani A K 1973 Inventory models with a mixture of backorders and lost sales. Nav. Res. Logist. Q. 20(2): 255-263

[37] Bogaschewsky R 1995 Natürliche Umwelt und Produktion. Wiesbaden: Gabler-Verlag

[38] Jabali O, Van Woensel T and de Kok A G 2012 Analysis of travel times and $\mathrm{CO}_{2}$ emissions in time-dependent vehicle routing. Prod. Oper. Manag. 21(6): 1060-1074

[39] Ligterink N E, Tavasszy L A and de Lange R 2012 A velocity and payload dependent emission model for heavyduty road freight transportation. Transp. Res. Part D: Transp. Environ. 17(6): 487-491
[40] Joglekar P N 1988 Note-Comments on "A quantity discount pricing model to increase vendor profits". Manage. Sci. 34(11): 1391-1398

[41] Abel N and Ruffini P. The Abel-Ruffini theorem. https://en. wikipedia.org/wiki/Abel-Ruffini_theorem. Accessed 3 May 2016

[42] Hadley G and Whitin T M 1963 Analysis of inventory systems. New Jersey: Prentice Hall

[43] Ouyang L Y, Wu K S and Ho C H 2004 Integrated vendorbuyer cooperative models with stochastic demand in controllable lead time. Int. J. Prod. Econ. 92(3): 255-266

[44] Zanoni S, Mazzoldi L and Jaber M Y 2014 Vendor-managed inventory with consignment stock agreement for single vendor-single buyer under the emission-trading scheme. Int. J. Prod. Res. 52(1): 20-31

[45] Ghosh A, Jha J K and Sarmah S P 2017 Optimal lot-sizing under strict carbon cap policy considering stochastic demand. Appl. Math. Model. 44: 688-704 